\title{
PERAN ACCOUNT PAYABLE TERHADAP KELANCARAN PEMBAYARAN TAGIHAN SUPPLIER DI PESONNA TUGU HOTEL YOGYAKARTA
}

\author{
Nita Riskiani ${ }^{1}$ dan Emmita Devi Hari Putri ${ }^{2}$ \\ ${ }^{l}$ Universitas Bina Sarana Informatika, Yogyakarta, Indonesia, Email:nita.riskiani@bsi.ac.id \\ ${ }^{2}$ Universitas Bina Sarana Informatika, Yogyakarta, Indonesia, Email:emita.evr@bsi.ac.id
}

\begin{abstract}
(20)
ABSTRAK

Histori Artikel

Submitted:

1 Oktober 2019

Reviewed:

15 Oktober 2019

Accepted:

1 November 2019

Published:

15 November 2019

Artikel ini untuk menganalisa proses pembayaran tagihan supplier di Pesonna Tugu Hotel Yogyakarta antara lain supplier melakukan tukar tanda terima, membuat payment voucher, pengiriman memo, dan proses overbooking. Proses pembayaran tagihan supplier terhadapat kendala antara lain supplier terlambat melakukan tukar tanda terima, purchasing dan receiving terlambat menyetorkan dokumen dan kurang lengkap, pengiriman memo yang terlambat dan proses overbooking yang terlambat. Account Payable mengatasi kendala dengan cara menghubungi supplier untuk segera melakukan tukar tanda terima, mengingatkan purchasing dan receiving untuk segera menyetorkan dokumen, proses pengiriman memo yang dilakukan pada akhir bulan, serta mengingatkan PT Pesonna Indonesia Jaya untuk segera melakukan overbooking. Peran dan tanggung jawab account payable sangat penting dalam proses pembayaran tagihan supplier, agar accont payable berjalan dengan lancar maka account payable harus menjalin komunikasi yang baik dengan supplier, purchasing, dan receiving.
\end{abstract}

Kata Kunci: Account Payable, Pembayaran Tagihan, Supplier

\section{THE ROLE OF THE PAYABLE ACCOUNT TOWARD THE SUPPLEMENT OF THE BILL PAYMENT AT PESONNA TUGU HOTEL YOGYAKARTA}

\begin{abstract}
The results of this study were to analyze the supplier bill payment process at Pesonna Tugu Hotel Yogyakarta, among others, suppliers exchanging receipts, making payment vouchers, sending memos, and overbooking processes. The process of paying supplier bills for obstacles includes suppliers being late in exchanging receipts, purchasing and receiving late submitting documents and not being complete, sending late memos and late overbooking processes. Accounts Payable overcome obstacles by contacting suppliers to immediately exchange receipts, remind purchasing and receiving to immediately deposit documents, process the sending of memos at the end of the month, and remind PT Pesonna Indonesia Jaya to immediately overbooking. The role and responsibility of account payable is very important in the process of payment of supplier bills, so that the account payable goes smoothly, then the account payable must establish good communication with suppliers, purchasing, and receiving.
\end{abstract}

Keywords : Accounts Payable, Bill Payment, Supplier 


\section{PENDAHULUAN}

Industri pariwisata saat ini sedang mengalami perkembangan yang sangat pesat. Perkembangan industri pariwisata tidak lepas dari beberapa hal pendukungnya, antara lain akomodasi, makanan dan minuman, serta obyek wisata. Salah satu akomodasi yang berperan dalam industri pariwisata adalah hotel. Hotel adalah salah satu jenis akomodasi yang menyediakan jasa pelayanan penginapan, makanan dan minuman. Hotel adalah suatu bentuk bangunan, lambang, perusahaan atau badan usaha akomodasi yang menyediakan pelayanan jasa penginapan, penyedia makanan dan minuman serta fasilitas jasa lainnya dimana semua pelayanan itu diperuntukan bagi masyarakat umum, baik mereka yang bermalam di hotel tersebut ataupun mereka yang hanya menggunakan fasilitas tertentu yang dimiliki hotel itu (Putri, 2016:12).

Pesonna Tugu Hotel Yogyakarta, adalah salah satu hotel berbintang tiga di Daerah Istimewa Yogyakarta. Letak hotel Pesonna Tugu sangat strategis karena berada di dekat Tugu Yogyakarta. Letak strategis sebuah hotel menjadi salah satu faktor yang mempengaruhi banyak tidaknya tingkat kunjungan tamu. Selain letak yang strategis, kualitas pelayanan menjadi kunci keberhasilan sebuah hotel. Pesonna Tugu Hotel; memiliki beberapa department, antara lain Accounting Department, Sales and Marketing Department, Human Resource Department, Front Office Department, Housekeeping Department, Engineering Department, Kitchen Department, Food and Beverage Department. Department tersebut saling bekerjasama untuk kelancaran dan menjaga kualitas pelayanan hotel. Accounting Department bertugas untuk mengurus biaya pengeluaran dan pendapatan di sebuah hotel. Melalui Accounting department ini dapat diketahui penghasilan yang diperoleh oleh hotel tersebut. Banyaknya kebutuhan yang harus dipenuhi di Pesonna Tugu Hotel, maka hotel harus membeli barang kebutuhan dari suplier. Salah satu permasalahan yang terjadi hotel tidak selalu mempunyai cukup dana untuk melakukan pembayaran kepada suplier pada saat itu juga, sehingga hotel melakukan kredit barang kepada suplier. Apabila hotel terlambat melakukan pembayaran tagihan setelah jatuh tempo, suplier tidak akan mengirim barang yang dibutuhkan hotel. Hal ini akan berpengaruh pada kegiatan operasional hotel.

Accounting mempunyai peranan yang sangat penting di dalam hotel, karena Accounting bertanggung jawab untuk mengendalikan kegiatan operasional keuangan. Accounting Department terdiri atas beberapa seksi yang saling terkait salah satunya adalah Account Payable. Peran Account Payable sangat penting dalam kelancaran operasional hotel yaitu dengan cara melakukan pembayaran tagihan tepat waktu, apabila account payable telat melakukan pembayaran supplier tidak akan mengirim barang ke hotel. Sehingga operasional hotel dapat terhambat karena tidak adanya barang yang dibutuhkan hotel.

\section{LITERATUR REVIEW}

\section{Supplier (pemasok)}

Supplier adalah pemasok langganan yang memberikan fasilitas kredit kepada perusahaan dan pemasok telah ditentukan oleh bagian pembelian (Gunawan, 2015:26). Pemasok adalah seseorang atau organisasi yang menawarkan atau memasarkan barang maupun jasa secara langsung ataupun tidak langsung (Tampubolon dalam Lestari, 2018:18).Uraian tersebut dapat disimpulkan bahwa pemasok adalah seseorang atau kelompok organisasi yang menyediakan barang atau jasa untuk dijual baik secara langsung atau tidak langsung.

\section{Jenis-jenis Pemasok}

Menurut Tampubolon dalam Lestari (2018:18) jenis-jenis pemasok ada dua yaitu:

Pemasok tipe cash keras adalah tipe pemasok yang selalu meminta pelanggannya untuk membayar secara tunai setiap transaksi yabg dilakukan.

Pemasok tipe tempo adalah tipe pemasok yang memberikan waktu untuk para 
pelanggannya dalam pembayaran setiap transaksi yang dilakukan.

\section{Pembayaran}

Pembayaran adalah berpindahnya sejumlah uang atau dana dari pembayaran kepada penerimanya, baik langsung maupun melalui jasa-jasa perbankan (Suyatno, dalam Lestari 2018:12). Suyatno dalam Lestari (2018:13) memaparkan terkait dengan jenisjenis pembayaran.

Pembayaran tradisional adalah pembayaran yang masih sederhana yang tidak memerlukan jasa bank sebagai mana yang terjadi di pedesaan, dimana di tempat tersebut belum ada jasa perbankan dan jika ada pasti memerlukan waktu yang lama untuk mendatangi bank dikarenakan jarak yang sangat jauh, dan tidak adanya alat transportasi yang memadai, sehingga sangat sulit untuk melakukan transaksi pembayaran selain pembayaran tradisional, bisa dikatakan pembayaran tradisional adalah pembayaran yang paling mudah.

$\begin{array}{ccc}\text { Pembayaran } & \text { modern } & \text { adalah } \\ \text { pembayaran yang dilakukan } & \text { dengan }\end{array}$
Pembayaran merupakam proses yang cukup rumit, dimana lembaga perbankan mempunyai peran yang sangat penting dan memerlukan jasa-jasa perantara karena tanpa jasa perantara tidak dapat terlaksana dengan cepat dan efisien.

\section{Tagihan}

Tagihan adalah klaim terhadap pihak lain berupa uang, barang atau jasa merupakan kewajiban pihak lain kepada entitas.Tagihan yang tidak didukung dengan janji tertulis disebut piutang usaha (Irma, 2017:35).

\section{METODE}

\section{Desain Penelitian}

Metode penelitian merupakan cara yang digunakan dalam penelitian dengan teknik mengumpulkan data. Metode penelitian merupakan penelitian yang digunakan untuk mengetahui fakta tanpa membandingkan fakta yang lain (Sugiyono, 2014:15).

Metode deskriptif bertujuan untuk mengungkapkan kejadian atau fakta yang terjadi selama penelitian berlangsung. Penelitian kualitatif adalah salah satu prosedur penelitian yang menghasilkan data deskriptif berupa ucapan atau tulisan dan perilaku orang-orang yang diamati Bogdam dan Taylor (dalam Alfianika, 2016:22). Metode deskriptif kualitatif merupakan penelitian yang memperoleh data-data seperti hasil penelitian, hasil wawancara, hasil pemotretan, catatan lapangan, analisis dokumen yang disusun oleh peneliti dilokasi penelitian, tidak dituangkan dalam bentuk dan angka-angka Gunawan (dalam Kamil, 2018:22).

Penelitian ini menggunakan metode pengambilan data penelitian deskriptif kualitatif yaitu metode penelitian yang mana data tersebut merupakan data dan kejadian atau peristiwa yang terjadi sesuai kejadian yang sebenarnya. Penulis mempunyai tujuan dalam melakukan penelitian ini yaitu untuk mengetahui peran Account Payable dalam kelancaran pembayaran tagihan di Pesonna Tugu Hotel Yogyakarta. Data yang diperoleh berupa data mengenai proses pembayaran tagihan, kendala yang dihadapi account payable dan cara mengatasi kendala yang terjadi di Pesonna Tugu Hotel Yogyakarta.

\section{Teknik Pengambilan Data}

Wawancara digunakan sebagai teknik pengumpulan data apabila peneliti ingin melakukan studi pendahuluan untuk menemukan permasalahn yang harus diteliti, dan apabila peneliti ingin mengetahui hal-hal dari responden yang lebih mendalam dan jumlah respondennya sedikit (Sugiyono, 2014:137). Penulis melakukan tanya jawab dengan beberapa pihak yang ada di Pesonna Tugu Hotel, baik dengan Assisten Accounting, Account Payable dan Human Resource Department (HRD). Proses wawancara dilakukan pada saat penulis melakukan on the job training pada bulan Agustus 2018. Wawancara dilakukan untuk mendapatkan informasi mengenai proses 
pembayaran tagihan kepada supplier, kendala account payable dalam proses pembayaran tagihan dan cara mengatasi kendala tersebut

Observasi adalah suatu teknik pengumpulan data yang mempunyai ciri yang spesifik bila dibandingkan dengan teknik yang lain (Sugiyono, 2014:145). Peneliti melakukan observasi secara langsung selama melakukan on the job training di Pesonna Tugu Hotel Yogyakarta, terkait dengan department Account Payable dalam menangani pembayaran tagihan di Pesonna Tugu Hotel Yogyakarta.

Dokumen merupakan catatan peristiwa yang sudah berlalu. Dokumen bisa berbentuk tulisan, gambar atau karya-karya monumental dari seseorang. Studi dokumen merupakan pelengkap dari penggunaan metode observasi dan wawancara dalam penelitian kualitatif (Sugiyono, 2014:240). Penulis mengambil beberapa sample data yang berkaitan dengan hotel yaitu seperti foto dan dokumen yang berkaitan dengan penelitian seperti invoice, bill giro, payment voucher, struktur organisasi hotel, dan lainnya.

Studi Pustaka adalah pengumpulan data yang dapat diperoleh dari berbagai sumber misalkan buku, jurnal, karya ilmiah, majalah, dan lain sebagainya (Satrianawati dalam Setiawati, 2018:18). Pada teknik studi pustaka peneliti mendapatkan informasi yang diperoleh dari buku-buku pariwisata dan perhotelan, laporan penelitian atau jurnal, artikel internet, dan sumber-sumber tertulis baik yang tercetak maupun elektonik lain sebagai acuan penelitian.

\section{HASIL DAN PEMBAHASAN}

\section{Proses Account Payable Saat Melakukan Pembayaran Tagihan di Pesonna Tugu Hotel Yogyakarta}

Account Payable mempunyai peran yang penting dalam aktifitas pembayaran tagihan ke supplier, karena ketika account payable terlambat melakukan pembayaran tagihan maka supplier akan memberhetikan pengiriman barang ke hotel. Sehingga proses produksi maupun operasional di Pesonna Tugu Hotel akan mengalami masalah.

Tugas account payable antara lain pencatatan semua utang-utang perusahaan dan menyiapkan pembayarannya yaitu Payment Voucher.

Proses pembayaran Tagihan di Pesonna Tugu Hotel Yogyakarta dimulai dengan proses pembelian barang, penerimaan barang, maka akan terjadi suatu tagihan. Proses pembayaran tagihan sebagai berikut:

1. Proses Pembelian barang

2. Proses Penerimaan Barang

3. Proses Pembayaran Tagihan

Tidak semua pembayaran tagihan supplier melalui receiving, beberapa pembayaran yang tidak melalui receiving antara lain:

1. Pembayaran Laundry

2. Pembayaran Cattering

3. Pembayaran SPA

\section{Kendala yang di hadapi Account Payable Pada Proses Pembayaran Tagihan di Pesonna Tugu Hotel Yogyakarta}

Pada proses pembayaran tagihan ada beberapa kendala yang menghambat proses pembayaran tagihan, sehingga pembayaran tagihan tidak sesuai dengan perjanjian atau jatuh tempo.

Supplier yang terlambat melakukan tukar tanda terima akan mengakibatkan proses pembayaran tagihan menjadi terlambat, seharusnya supplier melakukan proses tukar tanda terima pada awal bulan tetapi supplier sering melakukan proses tukar tanda terima pada pertengahan bulan hal tersebut dapat menghambat proses pembuatan Payment Voucher menjadi terhambat.

Receiving saat melakukan penyetoran dokumen Receiving Report (RR), kepada Account Payable yang kurang lengkap seperti kurangnya dokumen invoice, Purchase Order (PO). Hal ini terjadi karena purchasing terlambat memberikan dokumen purchase order ke pada receiving, sehingga receiving tidak dapat membuat dokumen receiving report.

Pada proses pengiriman memo ke PT Pesonna Indonesia Jaya, Account Payable 
harus melakukan proses pengiriman memo secepatnya. Karena saat account payable terlambat melakukan pengiriman memo maka proses overbooking juga akan mengalami keterlambatan.

Overbooking terjadi karena proses mentransfer sejumlah dana dari rekening PT Pesonna Indonesia Jaya ke rekening hotel. Sehingga jika overbooking mengalami keterlambatan, maka akan berpengaruh pada proses pembayaran yang dilakukan oleh account payable juga akan mengalami keterlambatan.

Keterlambatan Pembayaran pada saat supplier akan mendatangi hotel untuk menagihkan tagihan pembayaran yang belum juga dibayarkan oleh account payable sampai batas waktu yang sudah di janjikan oleh pihak hotel.

\section{Upaya Account Payable Mengatasi Kendala Pada Proses Pembayaran Tagihan di Pesonna Tugu Hotel Yogyakarta}

Upaya-upaya account payable dalam mengurangi atau mencegah kendala pada proses pembayaran tagihan, sehingga proses pembayaran tagihan dapat dilakukan sesuai dengan perjanjian atau jatuh tempo. Upaya account payable dalam mengatasi kendala adalah sebagai berikut:

Supplier terlambat melakukan tukar tanda terima, hal ini sering terjadi di Pesonna Tugu Hotel. Terlambatnya tukar tanda terima akan berpengaruh pada proses pembuatan payment voucher. Account payable dalam mengatasi masalah ini dengan cara menghubungi supplier untuk segera melakukan tukar tanda terima.

Untuk mengatasi terlambatnya penyetoran dokumen, account payable mengingatkan purchasing untuk segera membuat purchasing order agar receiving dapat membuat receiving report dan segera menyetorkan ke bagian account payable.

Untuk mengatasi kendala keterlambatan pengiriman memo, account payable melakukan proses pengiriman memo yang dilakukan pada saat akhir bulan, sehingga pada saat awal bulan PT Pesonna Indonesia
Jaya dapat melakukan overbooking dan account payable dapat segera melakukan pembayaran tagihan ke supplier.

Untuk mengatasi kendala keterlambatan overbooking, selain account payable melakukan proses pengiriman memo pada akhir bulan yang dilakukan account payable adalah dengan mengingatkan pusat bahwa account payable telah mengirimkan memo dan untuk segera melakukan overbooking.

Pada saat supplier mendatangi hotel dan melakukan penagihan pembayaran account payable akan berbicara kepada supplier untuk memberikan kelonggaran waktu untuk membayar tagihan tersebut, apabila supplier tidak mau memberikan waktu account payable akan mengokumunikasikan kepada accounting manager untuk berbicara ke pada PT Pesonna Indonesia Jaya untuk segera melakukan overbooking.

\section{SIMPULAN}

Pembayaran tagihan di hotel melalui beberapa proses yaitu proses pembelian barang, penerimaan barang, dan proses pembayaran tagihan. Pada awal bulan supplier melakukan tukar tanda terima kebagian account payable, data yang sudah terkumpul kemudian dicocokan dengan dokumen yang diberikan oleh receiving kemudian account payable membuat payment voucher yang ditanda tangani oleh accounting manager, general manager, dan account payable. Setelah itu account payable akan membuat memo yang dikirim ke PT Pesonna Indonesia Jaya untuk melakukan overbooking.

Kendala yang di hadapi account payable dalam proses pembayaran tagihan di Pesonna Tugu Hotel Yogyakarta yaitu terlambatnya supplier dalam melakukan tukar tanda terima, penyetoran dokumen dari receiving dan purchasing yang tidak tepat waktu, proses pengiriman memo dan overbooking yang terlambat atau tidak tepat waktu.

Cara mengatasi kendala dalam proses pembayaran tagihan yang terjadi di Pesonna Tugu Hotel Yogyakarta adalah account payable sudah memiliki cara-cara mengatasi kendala yang dihadapi dengan baik dan benar 
seperti ketika supplier terlambat melakukan tukar tanda terima, maka account payable akan menghubungi supplier untuk segera melakukan tukar tanda terima. Ketika purchasing dan receiving terlambat menyetorkan dokumen, account payable akan menegur dan meminta purchasing dan receiving untuk segera menyetorkan dokumen, dan saat pengiriman memo account payable akan melakukan pengiriman pada akhir bulan, sehingga overbooking dapat dilakukan pada awal bulan. Jika overbooking terlambat dilakukan accont payable akan mengomunikasikan dengan PT Pesonna Indonesia Jaya untuk segera mengecek memo dan melakukan overbooking.

\section{REFERENSI}

Alfianika, Ninit. (2018). Buku Ajar Metode Penelitian Pengajaran Bahasa Indonesia. Yogyakarta : CV. Budi Utama

Bahri, Syaiful. (2016). Pengantar Akuntansi. Yogyakarta : CV. Andi

Gunawan, Hendra. (2015). Aplikasi Pengolahan Data Akuntansi. Yogyakarta : CV.Andi Offset

Hartono dan Namira Ufrida Rahmi. (2018). Pengantar Akuntansi. Yogyakarta: Deepublish

Irma, Ramadhani. (2017). Akuntansi Dasar Jilid 2. Ponorogo : Uwais Ispirasi Indonesia

Kustini, Henny. (2017). General Hotel Management. Yogyakarta : CV. Budi Utama

Komar, Richard. (2014). Hotel Management. Jakarta : PT. Grasindo

Putri, Emmita Devi Hari. (2016). Pengantar Akomodasi dan Restoran. Yogyakarta: Deepublish
Sugiyono. (2016). Metode Penelitian Kuantitatif, Kualitatif, dan $R \& D$. Bandung : Afabeta

\section{BIODATA PENULIS}

Nita Riskiani merupakan dosen di Universitas Bina Sarana Informatika.

Emmita Devi Hari Putri, lahir di Kota Yogyakarta, 11 Januari 1987, sejak kecil sampai saat ini tinggal di Kota Yogyakarta. Dari Sekolah Dasar hingga SLTA sekolah di Yogyakarta dan melajutkan perkuliahan Diploma III jurusan perhotelan pada tahun 2006 di Sekolah Tinggi Pariwisata Ambarrukmo (STIPRAM) kemudian melanjutkan studi S1 pada tahun 2009 di Sekolah Tinggi Pariwisata Ambarrukmo (STIPRAM) jurusan Hospitality, lulus tahun 2011. Mengajar jurusan perhotelan di AKPAR "BSI Yogyakarta" sejak tahun 2013 hingga sekarang. Pada tahun 2015 telah menyelesaikan program pascasarjana di STIEPARI Semarang Jurusan Magister Manajemen Pariwisata.

Id Scholar:

https://scholar.google.co.id/citations?hl=id\& user $=j r Q q y U I A A A A J$ 